\title{
COLABORAÇÃO PREMIADA E O ESTADO DEMOCRÁTICO DE DIREITO: NOVOS ESTUDOS JURÍDICOS?
}

AWARD-WINNING COLLABORATION AND THE DEMOCRATIC STATE OF LAW: NEW LEGAL STUDIES?

COLABORACIÓN PREMIADA Y EL ESTADO DEMOCRÁTICO DE DERECHO: ¿NUEVOS ESTUDIOS JURÍDICOS?

Christiane do Vale Leitão ${ }^{1}$

Martonio Mont'Alverne Barreto Lima²

Resumo: O presente estudo tem por objetivo investigar a compatibilidade entre os dispositivos do diploma legal que disciplina o instituto da colaboração premiada - a Lei $n^{\circ} 12.580$, de 02 de agosto de 2013 - sua aplicação prática e compatibilidade com a ordem constitucional vigente, com o elenco de garantias fundamentais, materiais e processuais da Constituição Federal. Buscamos a análise do instituto da colaboração premiada de nosso ordenamento jurídico, como forma de colaboração com a justiça, no combate à

1 Martonio Mont'Alverne Barreto Lima é Professor Titular da Universidade de Fortaleza e Procurador do Município de Fortaleza

2 Christiane do Vale Leitão é advogada, mestranda em Direito Constitucional pela Universidade de Fortaleza. 
criminalidade. Nos dias atuais, esta colaboração tem sido objeto de muitos debates, visto que o texto normativo trouxe importantes consequências para a atuação das agências de poder punitivo estatal, como a conceituação legal do que seria uma organização criminosa e a regulação da colaboração processual e premiada. A partir da crítica de recentes decisões pelo Supremo Tribunal Federal, analisando-se ainda os efeitos e consequências práticas das disposições da nova Lei, procuraremos posição sobre sua constitucionalidade nas perspectivas formal e material.

Palavras-chave: Colaboração e delação premiada - Garantias Constitucionais - Proporcionalidade em sentido estrito.

Abstract: This study investigates the compatibility of the provisions of the legal statute governing the award-winning collaboration - Law No. 12,580, of August 2, 2013 - and its practical application and compatibility with the existing constitutional order, and with the list of basic, substantive and procedural safeguards of the Constitution. It analyzes the award-winning collaboration of our legal system, as a way of collaborating with justice in the fight against crime. Nowadays, this collaboration has been the subject of much debate, as the normative text had important consequences for the practice of state agencies with punitive power, such as the legal concept of what constitutes a criminal organization, and the regulation of procedural and award-winning collaboration. Based on the criticism of recent decisions by the Federal Supreme Court, it also analyzes the effects and practical consequences of the legal provisions, seeking to take a view on its constitutionality, from the formal and material perspectives.

Keywords: award-winning collaboration - Constitutional Guarantees - Proportionality in the strict sense.

Resumen: El presente estudio tiene por objetivo investigar la compatibilidad entre los dispositivos del diploma legal que disciplina el instituto de la colaboración premiada - la Ley n⿳ 12.580, de 2 de agosto de 2013 -, su aplicación práctica y su compatibilidad con el orden constitucional vigente, con el repertorio de garantías fundamentales, materiales y procesales de la Constitución Federal. Realizamos el análisis del instituto de la colaboración premiada de nuestro ordenamiento jurídico como forma de colaboración con la justicia en el combate a la criminalidad. En los días actuales esa co- 
laboración ha sido objeto de muchos debates, dado que el texto normativo trajo importantes consecuencias para la actuación de las agencias de poder punitivo estatal, como la conceptuación legal de lo que sería una organización criminal y la regulación de la colaboración procesal y premiada. A partir de la crítica de recientes decisiones del Supremo Tribunal Federal y analizando los efectos y consecuencias prácticas de las disposiciones de la nueva Ley, intentaremos tomar posición sobre su constitucionalidad desde el punto de vista formal y material.

Palabras clave: Colaboración y delación premiada; Garantías Constitucionales; Proporcionalidad en sentido estricto.

\section{INTRODUÇÃO}

\section{A cena nacional tem sido ocupada nos últimos tempos por escândalos político- econômico-financeiros, em que a exposição pública dos investigados - condenados já por antecipação e sem processo aos} olhos do país - parece ser a regra.

A par da espetacularização do inquérito policial e do processo, em que os agentes do poder punitivo assumem ares de guardiões da moralidade pública, em um processo paulatino de criminalização da prática política, surge para o esclarecimento dos crimes que se apuram a chamada colaboração premiada, na conformidade das palavras dos textos legais. Em virtude, porém, da imensa reportagem em todos os tipos de veículos de comunicação, todos os dias, o termo colaboração premiada passou a ser designado como delação premiada.

Há um evidente risco de imprecisão da linguagem que pode redundar ainda num risco teórico. O termo delação tem uma conotação precisa e pode ser identificado como a revelação feita em segredo, à margem da lei, em que aquele que delata esconde-se, e é assim mantido, a fim de assegurar não somente o sucesso de sua delação, como preservar a si, seus familiares e amigos e, principalmente, a seus interesses. Queremos, desta forma, esclarecer que o uso do termo delação premiada, ao longo deste artigo, implica apenas uma observação fática da realidade 
dos dias atuais: o termo popularizou-se, porém sua assimilação pela sociedade dáse desta forma. Somos sabedores deste limite semântico e não nos entregamos a ele: apenas queremos ser mais bem compreendidos sobre o expomos.

Não tem sido rara a chamada espetacularização seletiva de julgamentos pela imprensa no Brasil e noutros países. No julgamento da Ação Penal n 470 - conhecida como "julgamento do mensalão do Partido dos Trabalhadores" - ficou registrado o prejuízo da dogmática jurídica penal democrática, que também se deixou traduzir pela forma semântica. Lênio Luiz Streck, em diversos textos semanais, advertia do risco que se pode correr diante de tal compromisso: "E assim foi com a AP 470. Aquilo que a dogmática pregava e ensinava a vida toda foi liquidada paradoxalmente pelo mesmo esquema tático que a sustentou: a livre apreciação da prova e a busca da verdade real (que tem em seu ponto de estofo o velho inquisitivismo e, portanto, as respostas teleológicas). Sim. Há décadas que os livros de processo penal ensina(ra) $\mathrm{m}$ aquilo que foi utilizado como arma contra os próprios ensinadores e utentes em geral. É duro, mas foi o que ocorreu"3. Nesta esteira, é que as imprecisões dogmática e linguística, sem as devidas ressalvas, originam sérios riscos à democracia, a qual sempre conviveu com a possibilidade do regresso.

A Lei $n^{\circ}$ 12.850, de 2 de agosto de 2013 trouxe importantes conseqüências para a atuação das agências de poder punitivo estatal, como a conceituação legal do que seria uma organização criminosa e a regulação da colaboração processual e da delação premiada.

Embora o instituto da delação premiada já tenha surgido em momentos esparsos da legislação penal nacional, como no artigo 41 da Lei de n. ${ }^{\circ} 11.343$, de 23 de agosto de 2006, e na Lei n. ${ }^{\circ}$ 9.269, de 02 de abril de 1996, que introduziu o parágrafo quarto ao artigo 159 do Código Penal Brasileiro, ateremo-nos ao exame das regras da Lei $n^{\circ} 12.850 / 2013$, sob cuja égide tramitam os processos e inquéritos policiais da chamada "Operação Lava Jato" 4 .

3 Streck, Lênio Luiz. Como (não se) ensinava processo penal antes da "lava jato". Eis o busílis!, p.1.

4 Tem-se feito tabula rasa da expressa recomendação do Conselho Nacional de Justiça no sentido de que os agentes judiciários se abstivessem de usar os nomes com que tão criativamente a Polícia Federal batiza suas investigações. À época, o então Presidente do CNJ, ministro Gilmar Ferreira Mendes, afirmava que "... é preciso encerrar esse capítulo de marketing policial às custas do judiciário (...)". In: Luís Roberto Barroso. Judicialização, ativismo judicial e legitimidade democrática. http://www.oab.org. br/editora/revista/users/revista/ 12350666701742 18181901.pdf. Acesso em 05/06//2015. 
A partir da crítica das recentes decisões pelo Supremo Tribunal Federal, analisando ainda os efeitos e as consequências práticas das disposições da nova Lei, procuraremos posição sobre sua constitucionalidade nos planos formal e material.

Discorreremos aqui sobre os impactos dos institutos introduzidos pela nova legislação na prática processual penal e policial, saindo do plano meramente formal para o plano do concreto, ao rés do chão da realidade.

\section{O ADVENTO DA LEI No $12.850 / 2013$}

Com a Lei n 12.850 , de 02/08/2013, uma lacuna foi preenchida com a definição de organização criminosa e do disciplinamento da colaboração processual.

A origem da "delação premiada" no direito brasileiro remonta às Ordenações Filipinas, cuja seção criminal, constante do Livro V, vigorou de janeiro de 1603 até a entrada em vigor do Código Criminal de 1830.

O Título VI do "Código Filipino", que definia o crime de "Lesa Majestade", tratava da "delação premiada" no item 12; o Título CXVI, por sua vez cuidava especificamente do tema, sob a rubrica "Como se perdoará aos malfeitores que derem outros à prisão" e tinha abrangência para premiar, com o perdão, criminosos delatores de delitos alheios.

Seguimos com um breve descritivo dos textos normativos anteriores ao advento da nova lei ora em exame: a) Código Penal, artigo 159,4, extorsão mediante sequestro; b) lei dos crimes hediondos (Lei $\mathrm{n}^{\circ}$. 8072/90, artigo 80, parágrafo único (.); c) lei do crime organizado (Lei n. 9034/95, artigo 6. ); d) lei de proteção a vítimas e testemunhas (Lei nº 9.807/99 artigos 13 e 14 f); e) lei de lavagem de dinheiro (Lei $n^{\circ} .9 .613 / 98$ artigos $1 .^{\circ}$ e $5^{\circ}$ ); f) lei antitóxicos (Lei $n^{\circ}$. 10.409/2002, artigo 32, 2. ${ }^{\circ}$ ).

O atual texto legislativo surge no contexto da ratificação pelo Brasil, há quase dez anos, da Convenção das Nações Unidas contra o Crime Organizado Transnacional e supre, no âmbito do direito interno, uma série de lacunas da Lei $n^{\circ}$ 
9.034/95, revogada expressamente pela nova Lei, até mesmo no que respeita ao conceito de organização criminosa, ausente do diploma anterior e que encontra definição já no parágrafo primeiro do artigo primeiro:

Art. 1o - Esta Lei define organização criminosa e dispõe sobre a investigação criminal, os meios de obtenção da prova, infrações penais correlatas e o procedimento criminal a ser aplicado.

$\S 1^{\circ}$ - Considera-se organização criminosa a associação de 4 (quatro) ou mais pessoas estruturalmente ordenada e caracterizada pela divisão de tarefas, ainda que informalmente, com objetivo de obter, direta ou indiretamente, vantagem de qualquer natureza, mediante a prática de infrações penais cujas penas máximas sejam superiores a 4 (quatro) anos, ou que sejam de caráter transnacional.

$\S 2^{\circ}$ - Esta Lei se aplica também:

I - às infrações penais previstas em tratado ou convenção internacional quando, iniciada a execução no País, o resultado tenha ou devesse ter ocorrido no estrangeiro, ou reciprocamente;

II - às organizações terroristas internacionais, reconhecidas segundo as normas de direito internacional, por foro do qual o Brasil faça parte, cujos atos de suporte ao terrorismo, bem como os atos preparatórios ou de execução de atos terroristas, ocorram ou possam ocorrer em território nacional.

A colaboração, a conhecida delação premiada, teve seu disciplinamento no artigo $4^{\circ}$ da nova Lei:

Art. 4o - O juiz poderá, a requerimento das partes, conceder o perdão judicial, reduzir em até $2 / 3$ (dois terços) a pena privativa de liberdade ou substituí-la por restritiva de direitos daquele que tenha colaborado efetiva e voluntariamente com a investigação e com o processo criminal, desde que dessa colaboração advenha um ou mais dos seguintes resultados:

I - a identificação dos demais coautores e partícipes da organização criminosa e das infrações penais por eles praticadas; 
II - a revelação da estrutura hierárquica e da divisão de tarefas da organização criminosa;

III - a prevenção de infrações penais decorrentes das atividades da organização criminosa;

IV - a recuperação total ou parcial do produto ou do proveito das infrações penais praticadas pela organização criminosa;

V - a localização de eventual vítima com a sua integridade física preservada.

§ 1 - Em qualquer caso, a concessão do benefício levará em conta a personalidade do colaborador, a natureza, e as circunstâncias, a gravidade e a repercussão social do fato criminoso e a eficácia da colaboração.

§ 2ㅇ - Considerando a relevância da colaboração prestada, o Ministério Público, a qualquer tempo, e o delegado de polícia, nos autos do inquérito policial, com a manifestação do Ministério Público, poderão requerer ou representar ao juiz pela concessão de perdão judicial ao colaborador, ainda que esse benefício não tenha sido previsto na proposta inicial, aplicando-se, no que couber oart. 28 do Decreto-Lei n 3.689, de 3 de outubro de 1941 (Código de Processo Penal).

§ 3- - O prazo para oferecimento de denúncia ou o processo, relativos ao colaborador, poderá ser suspenso por até 6 (seis) meses, prorrogáveis por igual período, até que sejam cumpridas as medidas de colaboração, suspendendo-se o respectivo prazo prescricional.

§ 4 - Nas mesmas hipóteses do caput, o Ministério Público poderá deixar de oferecer denúncia se o colaborador:

I - não for o líder da organização criminosa;

II - for o primeiro a prestar efetiva colaboração nos termos deste artigo.

$\S 5$ - Se a colaboração for posterior à sentença, a pena poderá ser reduzida até a metade ou será admitida a progressão de regime ainda que ausentes os requisitos objetivos. 
§ 60 - O juiz não participará das negociações realizadas entre as partes para a formalização do acordo de colaboração, que ocorrerá entre o delegado de polícia, o investigado e o defensor, com a manifestação do Ministério Público, ou, conforme o caso, entre o Ministério Público e o investigado ou acusado e seu defensor.

$\S 70$ - Realizado o acordo na forma do $\S 60$, o respectivo termo, acompanhado das declarações do colaboradore de cópia da investigação, será remetido ao juiz para homologação, o qual deverá verificar sua regularidade, legalidade e voluntariedade, podendo para este fim, sigilosamente, ouvir o colaborador, na presença de seu defensor.

§ 8o - O juiz poderá recusar homologação à proposta que não atender aos requisitos legais, ou adequá-la ao caso concreto.

§ 9o - Depois de homologado o acordo, o colaborador poderá, sempre acompanhado pelo seu defensor, ser ouvido pelo membro do Ministério Público ou pelo delegado de polícia responsável pelas investigações.

$\S 10$ - As partes podem retratar-se da proposta, caso em que as provas auto-incriminatórias produzidas pelo colaborador não poderão ser utilizadas exclusivamente em seu desfavor.

$\S 11$-A sentença apreciará os termos do acordo homologado e sua eficácia.

$\S 12$ - Ainda que beneficiado por perdão judicial ou não denunciado, o colaborador poderá ser ouvido em juízo a requerimento das partes ou por iniciativa da autoridade judicial.

$\S 13$ - Sempre que possível, o registro dos atos de colaboração será feito pelos meios ou recursos de gravação magnética, estenotipia, digital ou técnica similar, inclusive audiovisual, destinados a obter maior fidelidade das informações.

$\S 14$ - Nos depoimentos que prestar, o colaborador renunciará, na presença de seu defensor, ao direito ao silêncio e estará sujeito ao compromisso legal de dizer a verdade.

$\S 15$ - Em todos os atos de negociação, confirmação e execução da colaboração, o colaborador deverá estar assistido por defensor. 
$\S 16$. Nenhuma sentença condenatória será proferida com fundamento apenas nas declarações de agente colaborador.

Juntamente com o novo e detalhado regramento, vimos, quase que instantaneamente, a disseminação do emprego da delação premiada como meio essencial e mesmo exclusivo de prova. Na chamada "Operação Lava Jato" as delações premiadas se sucedem, sendo mesmo a pedra angular de sustentação do edifício probatório de acusação.

Assim sendo, transcrevemos a recente decisão proferida pelo eminente Ministro Teori Zavascki,quando da homologação do Termo de acordo firmado pelo Sr. Paulo Roberto Costa, o mais significativo dos colaboradores de todo o esquema criminoso 5 :

Petição 5209 RELATOR: MIN. TEORI ZAVASCKI. REQTE. (S): MINISTÉRIO PÚBLICO FEDERAL PROC.(A/S)(ES): PROCURADOR-GERAL DA REPÚBLICA DECISÃO: 1. Trata-se de requerimento, formulado pelo Procurador-Geral da República, de homologação do "Termo de Acordo de Delação Premiada" de fls. 57/72, firmado entre o Ministério Público Federal - MPF e, como colaborador, Paulo Roberto Costa, conforme prevê o $\S 7^{\circ}$ do art. $4^{\circ}$ da Lei n. 12.850/2013. Informa o requerente que, a partir de procedimentos investigatórios no âmbito do Inquérito Policial n. 714/2009, foi possível identificar um conjunto de pessoas físicas e jurídicas envolvidas em operações ilícitas, entre as quais as "utilizadas inclusive para lavar dinheiro oriundo de crimes antecedentes praticados em detrimento da PETROBRAS". A primeira fase da investigação propiciou a deflagração da denominada "Operação Lava Jato", em março de 2014, "com a finalidade de apurar a atuação de organizações criminosas responsáveis pela operação de estruturas paralelas ao mercado de câmbio e lavagem de dinheiro, abrangendo um grupo de doleiros com âmbito de atuação nacional e transnacional". Encontram-se atualmente em curso, segundo a petição, mais de quarenta procedimentos investigatórios, no âmbito dos quais foram expedidos mandados de busca e apreensão, de conduções coercitivas e de prisão. Foram propostas, a partir dessas investigações, doze ações penais. Entre os investigados e acusados, um deles é Paulo Roberto Costa, que, estando preso, concordou em firmar o termo de colaboração ora submetido à homologação judicial, justificando-se a competência originária do Supremo Tribunal Federal para promover a decisão a respeito em face da especial circunstância de que, entre as

5 A exaustiva transcrição é importante em virtude do amplo destaque que o assunto ocupa atualmente no cotidiano político brasileiro, bem como por ser a primeira homologação, no âmbito da delação premiada, a ser confirmada pela última instância do Poder Judiciário brasileiro. 
pessoas indicadas como envolvidas nos delitos objeto da colaboração, figuram autoridades com prerrogativa de foro perante a Suprema Corte. Para o fim da verificação determinada pelo art. $4^{\circ}$, $\S 7^{\circ}$, da Lei $n^{\circ} 12.850 / 2013$, deleguei ao Juiz Márcio Schiefler Fontes, magistrado instrutor convocado para atuar neste Gabinete (art. $3^{\circ}$, III, da Lei 8.038/1990), a oitiva prevista naquele dispositivo, a teor do art. 21-A, § $1^{\circ}$, I, do RISTF. Realizada a audiência determinada, na Seção Judiciária da Justiça Federal de Curitiba/PR, juntou-se o respectivo termo e mídia digital em que consta a gravação audiovisual da oitiva do colaborador, na presença de sua defensora. 2. Dos documentos juntados com o pedido é possível constatar Juiz Schiefler efetivamente, há elementos indicativos, a partir dos termos do depoimento, de possível envolvimento de várias autoridades detentoras de prerrogativa de foro perante tribunais superiores, inclusive de parlamentares federais, o queatrai a competência do Supremo Tribunal Federal, a teor do art. 102, I, b, da Constituição. Registre-se, ademais, que, em relação aos fatos relacionados à mesma investigação, já aportaram a esse Supremo Tribunal Federal e foram a mim distribuídos diversos outros procedimentos, inclusive habeas corpus em favor do indicado colaborador e a Reclamação 17.623/ PR. 3. Afirmada a competência, examino o pedido de homologação. A constitucionalidade da colaboração premiada, instituída no Brasil por norma infraconstitucional na linha das Convenções de Palermo (art. 26) e Mérida (art. 37), ambas já submetidas a procedimento de internalização (Decretos 5.015/2004 e 5.687/2006, respectivamente), encontra-se reconhecida por esta Corte (HC 90688, Relator (a): Min. RICARDO LEWANDOVSKI, Primeira Turma, julgado em 12/02/2008, DJe-074 DIVULG 24-04-2008 PUBLIC 25-04-2008 EMENT VOL-0231604 PP-00756 RTJ VOL- 00205-01 PP-00263 LEXSTF v. 30, n. 358, 2008, p. 389-414) desde antes da entrada em vigor da Lei $n^{\circ} 12.850 / 2013$, que exige como condição de validade do acordo de colaboração a sua homologação judicial, que é deferida quando atendidos os requisitos de regularidade, legalidade e voluntariedade. A voluntariedade do acordo foi reafirmada pelo colaborador no elucidativo depoimento já mencionado, prestado judicialmente na presença e com a anuência de sua advogada, conforme demonstra a mídia juntada aos autos. À regularidade da documentação apresentada pelo Ministério Público se soma a legitimidade do procedimento adotado, com especial observância da Lei n 12.850/2013. Quanto ao conteúdo das cláusulas acordadas, é certo que não cabe ao Judiciário outro juízo que não o da sua compatibilidade com o sistema normativo. Sob esse aspecto, os termos acordados guardam harmonia, de um modo geral, com a Constituição e as leis, com exceção do compromisso assumido pelo colaborador, constante da Cláusula 12, segunda parte, da Cláusula 15, g e da Cláusula 17, parte final, exclusivamente no que possa ser interpretado como renúncia, de sua parte, ao pleno exercício, no futuro, do direito fundamental de acesso à Justiça, assegurado pelo art. $5^{\circ}$, 
XXXV, da Constituição. Fica, portanto, excluída da homologação, que ora se formaliza, qualquer interpretação das cláusulas acima indicadas que possa resultar em limitação ao direito fundamental de acesso à Jurisdição. 4. Ante o exposto, HOMOLOGO o "Termo de Acordo de Delação Premiada" de fls. 57/72, com a ressalva acima indicada, a fim de que produza seus jurídicos e legais efeitos perante qualquer juízo ou tribunal nacional, nos termos da Lei $n^{\circ} 12.850 / 2013$. Remeta-se, desde logo, ao juízo da $13^{\circ}$ Vara Federal da Subseção Judiciária de Curitiba/PR e, oportunamente, ao Superior Tribunal de Justiça, cópia da presente decisão, juntamente com cópia do acordo de colaboração, apondo-se em cada folha a identificação correspondente, a fim de que seja dado o devido cumprimento, no âmbito de atuação desses órgãos judiciários, devendo ser por eles observado, no que couber, o regime de sigilo imposto pelo art. $7^{\circ}$ da referida Lei $n^{\circ} 12.850 / 2013$. 135.Os demais pedidos, formulados em petição própria (v.g., cisão Márcio Schiefler Fontes idos expedientes e instauração de procedimentos autônomos, abertura de conta Gab. Ministro Teori Zavascki a. Juiz Instrutor.; - dos para repatriamento de valores), serão examinados em decisão Cumpra-se. Intime-se. Brasília, 29 de setembro o de 20146.

Diante destas considerações, tentaremos apresentar uma visão crítica sobre o tema. Apresentaremos a noção da garantia do direito ao silêncio e da presunção de inocência como direitos fundamentais e do devido processo legal penal, todos amparados, assegurados e transcritos no artigo $5^{\circ}$ da CF e a repercussão de sua renúncia quando do efetivo implemento da delação e da ressalva do compromisso assumido pelo colaborador, constante da Cláusula 12, segunda parte, da Cláusula 15, g e da Cláusula 17, parte final, exclusivamente no que possa ser interpretado como renúncia, de sua parte, ao pleno exercício, no futuro, do direito fundamental de acesso à justiça, assegurado também pelo artigo $5^{\circ}$, inciso XXXV.

Num segundo momento apresentaremos uma breve contextualização histórica e jurídica da relevância do aceite e ratificação pelo nosso país das Convenções de Palermo (art. 26) e Mérida (art. 37), ressaltando ainda que ambas já foram submetidas a procedimento de internalização através dos Decretos n 5.015/2004 e n 5.687/2006, respectivamente, bem como quando da produção normativa estatal e suas repercussões quando da implantação da Lei $\underline{n^{\circ} 12.850 / 2013}$. Posteriormente, analisaremos os critérios da adoção da teoria 6 http://www.stf.jus.br/portal/cms/verNoticiaDetalhe.asp?idConteudo=298599. Acesso em: 30/05/2015. 
para o enfrentamento da utilização da proporcionalidade em sentido estrito dos referidos direitos e garantias fundamentais, através do prisma do princípio da proporcionalidade, aplicados à Lei ora em exame, quando da interpretação no âmbito penal pelo ordenamento jurídico pátrio em confronto com os direitos e garantias do processo penal.

\section{O DIREITO AO SILÊNCIO E A PRESUNÇÃO DE INOCÊNCIA E OS EFEITOS DE SUA RENÚNCIA QUANDO DO COMPROMISSO DA DELAÇÃO}

A conceituação do direito ao silêncio encontra-se prevista no artigo $5^{\circ}$ da Constituição Federal, LXIII: "o preso será informado de seus direitos, entre os quais o de permanecer calado, sendo-lhe assegurada a assistência da família e de advogado". Foi previsto originalmente pelo princípio nemo tenetur se detegere ou nemo tenetur se ipsum accusare, que implica a proibição de qualquer tipo de tortura como via de acesso para extração de confissões.

A origem desse direito remonta ao século XVI e, hodiernamente, encontrase incorporado às convenções internacionais de direitos humanos e aos ordenamentos jurídicos das nações democráticas. Em nosso País, onde operamos o direito ao silêncio, em razão do princípio da legalidade, e de um processo penal garantista; o silêncio do investigado só pode ser vencido por procedimentos penais, jamais pela força, intimidação, ou por meio da coerção.

Ressaltamos ainda que o direito ao silêncio contrapõe-se frontalmente ao instituto da confissão como prova cabal de um crime dos regimes inquisitoriais. O conceito tradicionalista de que a confissão era a "rainha das provas" não mais se coaduna com o devido processo legal, e destoa da evolução das garantias fundamentais da pessoa humana, especialmente nos séculos XIX e XX.

Conforme previsto no art. 65, inciso III, alínea $d$ do Código Penal, o Estado pode aplicar as chamadas atenuantes ou vantagens penais para incentivar o réu a falar. É o que verificamos com a ocorrência do caso de confissão (réu confesso). Tal situação ocorre quando da utilização do instituto descrito pelo novo texto normativo de "colaboração criminal premiada", exatamente porque o delator 
não é um traidor; é sim um colaborador da justiça criminal, em especial do Ministério Público e da Polícia; perspectiva teórica já evidenciada anteriormente, quando da discussão a respeito da adequação do temo.

Em troca do seu auxílio nas investigações, o acusado renuncia a sua garantia constitucional ao silêncio, e de não fazer prova contra si, por uma recompensa mais relevante que seria uma redução na sua pena, em proporção que varia de $1 / 3$ a 2/3 ou ao perdão judicial, com base nas diversas leis que regulam o tema, ou em casos especiais, com a concessão de absolvição mediante o não oferecimento da denúncia contra ele, nos termos do art. 26, $n^{\circ} 3$, da Convenção de Palermo (Decreto n 5.015/2004); do art. 37, nº 3 da Convenção de Mérida (Decreto nº 5.687/2006) e do art. 28 do Código de Processo Penal.

Observamos ainda que tais benefícios encontram-se sempre vinculados à devida intervenção judicial. A redução da pena só é aplicada no momento da prolação da sentença condenatória (art. 387 do CPP c/c o art. 68 do CP), proferida pelo juiz competente, após o devido processo legal no contraditório pleno. $O$ perdão judicial é utilizado na fase da absolvição sumária, com base no art. 397, inciso IV, do CPP, combinado com o art. 107, inciso IX, do CP, logo após da constituição do contraditório escrito.

Nesse sentido, trazemos jurisprudência a demonstrar o procedimento de aplicação do instituto:

PENAL E PROCESSUAL. QUADRILHA ARMADA. ROUBO COM USO DE ARMA DE FOGO, CONCURSO DE AGENTES E RESTRIÇÃO DE LIBERDADE. POSSE E PORTE DE ARMA DE FOGO. INÉPCIA DA DENÚNCIA. PRELIMINAR REJEITADA. DELAÇÃO PREMIADA. POSSIBILIDADE DO PERDÃO JUDICIAL. TESES ABSOLUTÓRIAS REJEITADAS. CRÍTICA INFUNDADA DA DOSIMETRIA. 1 RÉUS CONDENADOS POR INFRINGIR O ARTIGO 288, PARÁGRAFO ÚNICO, ALGUNS O ARTIGO 157, § 2 , INCISOS I, II E V, DO CÓDIGO PENAL E OUTROS OS ARTIGOS 12 E 16 DA LEI 10.826/03, EIS QUE INTEGRARAM GRUPO CRIMINOSO ARMADO VOLTADO À PRATICA DE ROUBOS DE CARGAS NAS RODOVIAS DO DISTRITO FEDERAL, ALÉM DA ASSOCIAÇÃO PARA A REALIZAÇÃO DE ESTELIONATOS E PARA A AQUISIÇÃO FRAUDULENTA DE AUTOMÓVEIS. 2 NÃO SE COGITA DE INÉPCIA DA DENÚNCIA SE OS RÉUS TÊM AMPLAS CONDIÇÕES DE SE DEFENDERDIANTEDAENUNCIAÇÃODOSFATOSNELACONTIDA,SENDO 
DISPENSÁVEL QUE DESCREVA PORMENORIZADAMENTE A CONDUTA DE CADA UM DELES PARA O ENQUADRAMENTO NA MOLDURA TÍPICA, SOB PENA DE INVIABILIZAR A AÇÃO PENAL. 3 A DELAÇÃO PREMIADA PODE RESULTAR NO PERDÃO JUDICIAL OU NA REDUÇÃO DA PENA, CONFORME ARTIGOS 13 E 14 DA LEI 9.807/99, OS QUAIS ESTIPULAM PARA CONCESSÃO DESSES BENEFÍCIOS, DENTRE OUTROS REQUISITOS, QUE A COLABORAÇÃO EFETIVA E VOLUNTÁRIA DO AGENTE PROPICIE A APURAÇÃO DO CRIME. O AGENTE FAZ JUS AO BENEFÍCIO QUANDO A INFORMAÇÃO QUE FORNECEU TENHA SE REVELADO IMPRESCINDÍVEL PARA IDENTIFICAR OS COAUTORES DOS CRIMES, ATÉ ENTÃO DESCONHECIDOS DA POLÍCIA CIVIL. 4 A DELAÇÃO DE UM DOS RÉUS, OS DEPOIMENTOS DOS POLICIAIS, AS ESCUTAS TELEFÔNICAS E A APREENSÃO DA RES FURTIVA E DE ARMAS DE FOGO COMPROVAM E JUSTIFICAM A CONDENAÇÃO. EM RELAÇÃO À DOSIMETRIA, O PEQUENO ACRÉSCIMO DECORRENTE DA REINCIDÊNCIA EM RELAÇÃO A ALGUNS RÉUS ESTÁ PROPORCIONAL E PLENAMENTE JUSTIFICADO. 5 APELAÇÕES DE DOIS RÉUS NÃO CONHECIDAS. RECURSO DE UM DOS RÉUS PROVIDO E OS DOS DEMAIS DESPROVIDOS. (TJ-DF - APR: 383746720108070001 DF 0038374-67.2010.807.0001, Relator: GEORGE LOPES LEITE, Data de Julgamento: 08/03/2012, $1^{\text {a }}$ Turma Criminal, Data de Publicação: 16/04/2012, DJ-e Pág. 304).

Há ainda a figura da imunidade à persecução; como algo que muito se assemelha ao acordo de leniência dos artigos 86 e 87 da Lei $n^{\circ}$ 12.529/2011, e que ocorre mediante o arquivamento da investigação criminal pelo Ministério Público, sob controle judicial anômalo, nos termos do art. 28 do CPP. Todas essas sanções premiais destinam-se a motivar a colaboração do indiciado, a respeito da elucidação de fato próprio ou de terceiros, nos termos da Lei n 9.807/99, ou de outras que lhe são correlatas, inclusive a lei de lavagem de dinheiro (Lei nº 9.613/98).

No cenário constitucional, o direito de não produzir prova contra si resolvese no direito de permanecer em silêncio em qualquer órgão ou instância. Segundo a Ministra Carmen Lúcia, Relatora do Habeas Corpus n 113.665/DF, "o direito ao silêncio mencionado na vasta e sedimentada jurisprudência deste STF refere-se, como é óbvio, ao direito de se calar para não se autoincriminar, nos termos constitucionalmente assegurados (artigo 50, inciso LXIII, da Constituição brasileira)".

Importante relembrarmos que sempre em obiter dictum, indiciados e até mesmo as testemunhas (CPC, art. 406, I, c/c CPP, art. 3o, e Lei no 1.579/52), dispõem da prerrogativa contra a autoincriminação, consoante tem proclamado a 
jurisprudência constitucional do Supremo Tribunal Federal (RTJ 172/929-930, Rel. Min. Sepúlveda Pertence - RDA 196/197, Rel. Min. Celso de Mello - HC 78.814/ PR, Rel. Min. Celso de Mello, v.g.)".

Ressaltamos ainda que o juiz só decidirá sobre o quanto o colaborador será beneficiado ao final do processo, após a análise da eficácia da informação prestada, pois nos termos do §10, as partes poderão se retratar do acordo firmado, "caso em que as provas autoincriminatórias produzidas pelo colaborador não poderão ser utilizadas exclusivamente em seu desfavor". Em uma interpretação a contrario senso, podemos concluir que as provas e os elementos de informação advindos da colaboração só não poderão ser utilizados em prejuízo do colaborador, servindo, entretanto, para a condenação dos demais integrantes da organização criminosa, o que por si só, ao que nos parece, pode comprometer mesmo o seu teor. Ainda que tenhamos a cautela da comprovação efetiva do relato do colaborador, não há que descartarmos a busca do homem por sua liberdade a qualquer custo, e as armadilhas da teoria diante da experiência de vida do homem, ou como preferia Goethe: "Cinzenta, meu caro amigo, é toda teoria, e verde somente a árvore dourada da vida"7. Mais: reside aqui a tentação de incriminação do outro, no afã de livrar-se das penalidades do sistema. Nem de longe defendemosa impunidade. Por outro lado, a punição não deve ser conseguida a qualque custo. A teoria da democracia muito caminhou a partir dos pressupostos da modernidade, ou seja, desde a Revolução Francesa até os dias atuais. Foi com este acontecimento político que a igualdade ingressou na centralidade do conceito de democracia, juntamente com garantias pessoais a acusados. Desta forma, como consequência da mesma Revolução, restou pacificado o entendimento que os resultados democráticos não são importantes e necessários em si próprio; são importantes e necessários desde que advenham estes resultados democráticos de processos igualmente democráticos. Com outras palavras, o direito de punir, a punição, a aplicação da penalidade ao criminoso, ante a perspectiva da teoria da democracia da modernidade, não deverá vir isoladamente, como produto a qualquer custo, em nome de uma abstração de ideal de justiça; deverá resultar este direito de $\overline{7 \mathrm{GOETHE}}$, J. W. Faust, p.66 No original: "Grau, teurer Freund, ist alle Theorie; und grün des Lebens goldenen Baum". 
punir, a punição e a apicação da pena de processos garantidores das liberdades que dispõem os acusados em sua defesa.

O procedimento de lavratura do termo de colaboração premiada deve ser efetuado pelo Delegado de Polícia ou pelo representante do Ministério Público, conforme determina o artigo $6^{\circ}$, da Lei, e deve conter: um relato da colaboração e seus possíveis resultados; as condições da proposta do Ministério Público ou do Delegado de Polícia; a declaração de aceitação do colaborador e de seu defensor; as assinaturas do Delegado de Polícia ou do representante do Ministério Público, do colaborador e de seu defensor; e, por fim, as medidas de proteção ao colaborador e à sua família, caso necessário.

Damásio de Jesus faz uma distinção entre delação e delação premiada, segundo ele:

Delação é a incriminação de terceiro, realizada por um suspeito, investigado, indiciado ou réu, no bojo de seu interrogatório (ou em outro ato). Já a delação premiada configura aquela incentivada pelo legislador, que premia o delator, concedendo-lhe benefícios (redução de pena, perdão judicial, aplicação de regime penitenciário brando). ${ }^{8}$

Nesse sentido, o instituto da delação premiada está inserido no âmbito do chamado direito penal premial, devendo ser entendido como um mal menor imposto ao indivíduo que, depois do cometimento de uma conduta punível pelo direito penal, realiza conduta colaborativa destinada a diminuir ou elidir a pena prevista para o ilícito originariamente cometido.

Por fim, importante se faz mencionar a exceção do compromisso assumido pelo colaborador, constante da Cláusula 12, segunda parte, da Cláusula 15, g e da Cláusula 17, parte final, exclusivamente no que possa ser interpretado como renúncia de sua parte ao pleno exercício, no futuro, do direito fundamental de acesso à justiça, assegurado pelo art. $5^{\circ}$, XXXV, da Constituição Federal Fica, portanto, excluída da homologação, que ora se formaliza, qualquer interpretação das cláusulas anteriormente indicadas que possa resultar em limitação ao direito fundamental de acesso à jurisdição.

8 Id.Delação Premiada, pp. 26/27. 
Sobre o princípio da presunção de inocência não vislumbramos lesão ou ameaça ao direito do delator/colaborador em razão das ressalvas do compromisso com a verdade e com a possibilidade de retratação, conforme disposições descritivas dos incisos de n. ${ }^{\circ} 10$ e 16 , da nova Lei.

A Constituição da República ampara expressamente este princípio em seu artigo $5^{\circ}$, inciso LVII, o qual dispõe não haver culpado até transitar em julgado sentença penal condenatória, significando que não bastam meros indícios ou a existência de qualquer procedimento contra o acusado, mas sim a prolação de sentença penal condenatória que esteja transitada em julgado.

Necessário lembrarmos que, apesar do entendimento de parte da doutrina que alega que a presunção de inocência não esteja expressa no rol fundamental, justificando que a disposição do artigo $5^{\circ}$, inciso LVII da Constituição refere-se ao princípio da "não culpabilidade", o próprio Supremo Tribunal Federal tem aplicado essa expressão em recentes julgados.

O Brasil tem ratificado tratados internacionais que privilegiam a presunção da inocência, fazendo das normas supralegais um forte argumento para a inserção deste princípio no ordenamento nacional. Notamos isto no artigo $8^{\circ}, 2$ da Convenção Americana dos Direitos Humanos, assinada pelo Brasil no Pacto de São José da Costa Rica, que, além de garantir a presunção de inocência, traz um rol de direitos do acusado.

Da mesma forma o Estatuto de Roma, criador do Tribunal Penal Internacional, aprovado pelo Brasil através do Decreto Legislativo $n^{\circ} 112$, de 06 de junho de 2002, elenca garantias que aduzem ao princípio do estado de inocência em seu artigo 66:

Presunção de Inocência 1. Toda a pessoa se presume inocente até prova da sua culpa perante o Tribunal, de acordo com o direito aplicável. 2. Incumbe ao Procurador o ônus da prova da culpa do acusado. 3. Para proferir sentença condenatória, o Tribunal deve estar convencido de que o acusado é culpado, além de qualquer dúvida razoável.

A posição clara do Estado Brasileiro em ratificar tais documentos internacionais que amparam o princípio da inocência fez com que a solução encontrada e 
utilizada na aplicação do princípio da não culpabilidade como sinônimo do princípio da presunção/estado de inocência encerrasse maiores discussões acerca de possíveis distinções entre uma coisa e outra, o que outrora ocupou a atenção dos juristas.

\section{A LEI No $12.850 / 13$ E A SUA INTERNALIZAÇÃO}

A Convenção das Nações Unidas contra o Crime Organizado Transnacional, mais conhecida como a Convenção de Palermo, é o principal instrumento jurídico de combate ao crime organizado transnacional. Foi aprovada pela ONU em $15 / 11 / 2000$ e entrou em vigor no dia 29/09/2003. Tem como objetivo promover e reforçar a estreita cooperação internacional a fim de enfrentar o crime organizado no mundo globalizado.

São três protocolos com áreas específicas abordadas pelo crime organizado: o Protocolo Relativo à Prevenção, Repressão e Punição do Tráfico de Pessoas, em Especial Mulheres e Crianças; o Protocolo Relativo ao Combate ao Tráfico de Migrantes por Via Terrestre, Marítima e Aérea; e o Protocolo contra a Fabricação e o Tráfico Ilícito de Armas de Fogo, suas peças e componentes e munições.

Com o advento do Decreto de no 5.015/04, a Convenção de Palermo passou a integrar o ordenamento jurídico brasileiro. De acordo com o artigo da 2a da referida Convenção, "grupo criminoso organizado" é aquele estruturado de três ou mais pessoas, existente há algum tempo e atuando em conjunto com o propósito de cometer uma ou mais infrações graves, com a intenção de obter, direta ou indiretamente, um benefício econômico ou outro benefício material.

A lavagem de dinheiro é crime previsto em tratados internacionais ratificados pelo Brasil, a saber: as Convenções das Nações Unidas contra a Corrupção (Mérida, 2003), contra o Crime Organizado Transnacional (Palermo, 2000) e contra o Tráfico Ilícito de Entorpecentes e Substâncias Psicotrópicas (Viena, 1988), assim como a Convenção Interamericana contra o Terrorismo (Barbados, 2002) e a Convenção da OCDE sobre Corrupção de Funcionários Públicos Estrangeiros em Transações Comerciais Internacionais (Paris, 1997). 
Em todos esses instrumentos, os Estados membros se obrigaram a tipificar o crime de lavagem de ativos. Todas essas convenções foram devidamente integradas ao ordenamento jurídico brasileiro, de acordo com o procedimento bifásico de formação de vínculos convencionais. Portanto, são tratados em vigor, com força de lei federal ordinária.

Em consonância com posição majoritária adotada pelo Supremo Tribunal Federal, a partir do ano de 2008, no julgamento dos processos HC 87.585/TO e RE 466.343/SP, estabeleceu-se a natureza supralegal desses tratados de direitos humanos ratificados pelo Brasil, sem a observância da formalidade prevista no art. 5. ${ }^{\circ}$ § $3^{\circ}$ da Constituição Federal; ou seja, estão hierarquicamente acima das leis infraconstitucionais, porém abaixo da Constituição.

Por outro lado, há quem defenda, amparado pela cláusula de abertura prevista no $\S 2^{\circ}$ do mesmo art. $5^{\circ}$ da Constituição Federal, a natureza constitucional desses tratados e convenções de direitos humanos, ainda que não tenham ingressado no ordenamento com status de Emenda Constitucional, por meio do procedimento privilegiado disposto no art. $5 .^{\circ} \mathrm{o}, \S 3$ da Constituição Federal ${ }^{9}$. Esta posição, que nos parece a mais razoável, confirma o caráter universal que se pretende da democracia e dos direitos humanos. Em outras palavras, pensa-se no homem e seus nexos com sociedade e estado como espécie, e não separado por nacionalidades.

Na verdade, os antecedentes de tais premissas já se encontram na propositura kantiana da Paz Perpétua de 1795/96. Nesta obra menos idealista, Kant discorre sobre a construção de um "direito cosmopolita" entre as nações e os povos (ou na sua linguagem, o Weltbürgerrecht). O aspecto menos idealista da obra de um filósofo idealista deixa-se comprovar pelo fato de que o projeto de paz eterna proposto por Kant possui por base o direito: numa perspectiva nacional e internacional. O fundamento da paz a ser atingida entre os homens não cairia do céu; resultaria da ação concreta entre homens e nações. Já antes, em 1775, o mesmo Immanuel Kant utilizaria o mesmo conceito - direito cosmopolita - para

9 Cf: Flávia Piovesan: Direitos humanos e o direito constitucional internacional. São Paulo: Max Li-

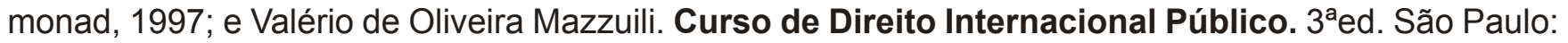
RT, 2009. 
propor uma "ideia para uma história geral com intenção cosmopolita"10. Com mais vigor, Kant deixa claro nos "segundo e terceiro artigos definitivos"11 para uma paz perpétua, respectivamente: "o direito internacional deve ser fundado por uma Federação de Estados livres" e "o direito cosmopolita deve ser limitado pelas condições da hospitalidade geral"12.

Parece evidente, então, que a tentativa de validade internacional de normas, especialmente aquelas a envolverem a aplicação penal, foi objetivo perseguido há bastante tempo. Recepcionar a doutrina nada mais corresponderia do que à aceitação dos pressupostos racionais de aplicação do direito internacional, com bases democráticas.

\section{O PRINCÍPIO DA PROPORCIONALIDADE EM SENTIDO ESTRITO} APLICADO NA APLICAÇÃO DA LEI.

A proteção dos direitos fundamentais decorre da dúplice função exercida pelos princípios constitucionais, quais sejam as de reconhecer tais direitos fundamentais e dimensionar os padrões e os limites de atuação do estado democrático de direito, inclusive no âmbito penal, delineando os contornos constitucionais do ius puniendi estatal.

A proporcionalidade em sentido estrito mostra-se particularmente importante quando o magistrado possa ver-se tentado a endurecer desmedidamente a pena, em razão do clamor social ou do imperativo de intimidar potenciais criminosos, sacrificando, em nome de hipotéticas vantagens coletivas, a liberdade individual e as perspectivas de ressocialização do agente. Neste sentido é que a objetividade do texto legal e a razão democrática devem impor ao magistrado um limite seguro para a democracia, o que vale dizer para os cidadãos, mas igualmente para a própria democracia que caracteriza o estado de direito. Desta forma, julgamentos "conforme a consciência do juiz" ou resultante de operações hermenêuticas de

10 KANT, Immanuel. Idee zu einer allgemeinen Geschichte in weltbürgerlicher Abischt, pp. A395ss.

11 KANT, Immanuel. Zum ewigen Frieden, pp. 208-213. No original: "Das Völkerrecht sol auf einen Föderalism freier Staaten gergündet werden"; "Das Weltbürgerrecht soll auf Bedingungen der allgemeinen Hospitalität eingeschränkt sein".

12 ld.,ib. 
subjetividades, antes de comprometerem o resultado interno das democracias que recepcionam tais Tratados e Convenções, redundam no grave compromisso da qualidade das relações internacionais e nos esforços que são realizados para a efetivação dos direitos humanos na escala supranacional.

A existência de parâmetros subjetivos, que se baseiam na astuta construção de princípios para todos os gostos - ou mesmo na "pan-princiopiologia" - tem demonstrado largamente o fracasso de diversos pontos do direito internacional e dos agentes punitivos. Nações poderosas - bélica e economicamente - restam imunes de punições internacionais, desencadeando sérias desconfianças da comunidade internacional. Como consequência, aquelesque sempredesconfiaram do sistema internacional agem como entendem, na defesa de seus interesses regionais específicos.

Assim como a necessidade estabelece que a escolha pelo magistrado das opções menos gravosas, de forma a não sujeitar o réu a privações e a constrangimentos desnecessários em razão do princípio da Dignidade Humana e demais garantias do Processo penal, ressaltamos que pode ser detectado prejuízo quando da aplicação ao caso concreto a incompatibilidade do instituto da delação com o exercício da defesa do acusado, tanto da defesa técnica, quanto da autodefesa, que se mostram interligadas numa postura do delator como acusador de si mesmo, em franca dissonância com o princípio do contraditório e da ampla defesa.

Sobre o princípio da proporcionalidade, Ingo. W. Sarlet escreve que:

Na seara do direito penal (e isto vale tanto para o direito penal material, quanto para o processo penal) resulta - como já referido - inequívoca a vinculação entre os deveres de proteção (isto é, a função dos direitos fundamentais como imperativos de tutela) e a teoria da proteção dos bensjurídicos fundamentais, como elemento legitimador da intervenção do Estado nesta seara, assim como não mais se questiona seriamente, apenas para referir outro aspecto, a necessária e correlata aplicação do princípio da proporcionalidade e da interpretação conforme a Constituição. Com efeito, para a efetivação de seu dever de proteção, o Estado - por meio de um dos seus órgãos ou agentes - pode acabar por afetar de modo desproporcional um direito fundamental (inclusive o direito de quem esteja sendo acusado da violação de direitos fundamentais de terceiros). Esta hipótese corresponde às aplicações 
correntes do princípio da proporcionalidade como critério de controle de constitucionalidade das medidas restritivas de direitos fundamentais que, nesta perspectiva, atuam como direitos de defesa, no sentido de proibições de intervenção (portanto, de direitos subjetivos em sentido negativo, se assim preferirmos). O princípio da proporcionalidade atua, neste plano (o da proibição de excesso), como um dos principais limites às limitações dos direitos fundamentais, o que também já é de todos conhecido e dispensa, por ora, maior elucidação ${ }^{13}$.

Sem dúvidas que não podemos abrir mão dos princípios para uma adequada reação ao que prescrevem constituição e lei. O que queremos deixar claro é que tais atividades interpretativas não podem: a) ter por base o convencimento subjetivo do julgador; b) não podem atribuir ao mesmo princípio aplicação em todas as direções: ou se resolve construir o estado de direito nesta ou naquela direção, e isso tem como consequência a vinculação semântica dos textos constitucionais e legais na direção que o poder constituinte determinou.

\section{CONSIDERAÇÕES FINAIS}

Estas considerações, evidentemente, não esgotam as questões que podem ser suscitadas ante a Lei 12.850/13, nem mesmo aprofundam a discussão dos temas abordados, sendo apenas uma análise superficial da lei feita à guisa de conhecimento.

O valor probatório da delação premiada como um meio de prova é complexo para ser apurado, e há de se destacar que atualmente existe uma série de dispositivos cuidando do instituto da delação premiada.

Há que questionarmos a moralidade de tal instituto, já que o Estado, ao se utilizar da figura do colaborador, "premia" o participante de organização criminosa que "trai" os demais. Neste sentido, leciona Zaffaroni que:

(...) a impunidade de agentes encobertos e dos chamados 'arrependidos' constitui uma séria lesão à eticidade do Estado, ou seja, ao princípio que forma parte essencial do Estado de Direito: (...) o Estado está se valendo da cooperação de um delinqüente, comprada ao preço da sua

13 Sarlet, Ingo. Wolfgang. Constituição e proporcionalidade: o direito penal e os direitos fundamentais entre proibição de excesso e de insuficiência, p. 24. 
impunidade para 'fazer justiça', o que o Direito Penal liberal repugna desde os tempos de Beccaria ${ }^{14}$.

Não obstante, podemos afirmar que se a lei é positiva em alguns pontos (por exemplo, na tipificação adequada de organização criminosa), traz disposições passíveis de críticas, como a colaboração premiada e a infiltração de agentes, demandando uma cuidadosa interpretação por parte dos operadores do direito, já que, em um Estado Democrático de Direito há interesses mais relevantes do que a simples apuração de uma infração penal, por mais grave que ela possa parecer.

Assim, é possível dizer que a mera previsão legal da utilização de colaboração premiada como instrumento de prova no processo penal, a par de discussões éticas, não viola princípios constitucionais de garantia do acusado ou regras processuais sobre aferição da prova. No aspecto processual, os problemas não estão na simples previsão normativa da cooperação pós-delitiva, mas sim na forma de sua efetiva utilização. Portanto o mais relevante na matéria será a adequada aplicação do instituto com a observância de enunciados fundamentais que decorrem da particularidade desse meio de prova e de sua correlação com o princípio da presunção de inocência e o direito ao silêncio.

Como dissemos anteriormente, os conjuntos nacional e internacional da legislação punitiva - e de seu processo - advêm da modernidade democrática. Por modernidade democrática entendemos aqui os preceitos da teoria da democracia fixados a partir da Revolução Francesa, com sua radicalidade de realização da igualdade entre os homens. Antes de se tornar prática, esta Revolução foi crítica, foi pensamento; tarefa do Iluminismo. Na esteira do ideário iluminista, como vimos em Kant, prevalece o caráter humano não somente como centro da investigação filosófica, porém como destinatário do direito internacional e do "direito cosmopolita". Dado que a colaboração premiada possui suas experiências no cenário internacional e que os crimes como lavagem de dinheiro alcançam e envolvem distintos atores de diversos países, a necessidade de entendimentos internacionais sobre sua aplicação salta aos olhos. Em todo caso, como herdeiros da tradição iluminista que é o direito internacional da atualidade, não lhe poderá

14 ZAFFARONI. Eugenio Raul. Crime organizado: uma categoria frustrada, p. 45 
ser menos relevante o respeito à ampla defesa, à integridade física e psíquica dos acusados, tampouco a observação até mesmo a pouca - ou nenhuma - dignidade que lhes resta. Não observar tal pressuposto, equivale a dar significativos passos atrás na busca pela paz entre homens e nações.

\section{REFERÊNCIAS DAS FONTES CITADAS}

GOETHE, Johann Wolfgang. Faust - der Tragödie. Kommentiert von Erich Künz. M6unchen: Verlag C. H. Beck, 1996.

JESUS, Damásio Evangelista de. Delação Premiada. Brasília: Revista Justilex, ano IV, n. 50, fevereiro de 2006.

KANT, Immanuel. Idee zur allgemeinen Geschichte in weltbürgerlicher Abisicht. Wissenschaftliche Buchgesellschaft: Darmstadt, 1983.

Zum ewigen Frieden. Ein philosophischer Entwurf. Wissenschaftliche Buchgesellschaft: Darmstadt, 1983.

SARLET, Ingo Wolfgang. Constituição e proporcionalidade: o direito penal e os direitos fundamentais entre proibição de excesso e de insuficiência. Revista Brasileira de Ciências Criminais, 2004: www.mundojuridico.adv.br. Acesso em 12.07.2005.

STRECK, Lênio Luiz. Como (não se) ensinava processo penal antes da "lava jato". Eis o busílis!. http:// www.conjur. /2015-jul-09/senso-incomum-nao-ensinava-proces-so-penalantes-lava-jato. Acesso em 09.07.2015.

ZAFFARONI. Eugenio Raul. Crime organizado: uma categoria frustrada. Discursos sediciosos: crime, direito e sociedade. Rio de Janeiro: Revan, ano 1, v. 1, 1996.

Recebido em: set/2015

Aprovado em: jul/2016 